\title{
DE INSTELLINGen VAN VOORzorg IN NEDERLANo.
}

De Staats-Courant van 22 Januarij behelst een rapport dd. September ll. van den Nederlandsche gedelegeerden bij het Congrès des Institutions de Préroyance, hetwelk in den verleden zomer te Parijs werd gehouden, en waaromtrent wij reeds, in afwachting van de officieele compte-rendus, een en ander aan onze lezers mededeelden (zie Economist 1878, pag. 739.)

De verschijning dier officieele verslagen gaat niet vlug, ofschoon het stenographische werk der publieke zittingen $1-6 \mathrm{Julij}$ toch wel sedert lang gereed zal zijn; meer tijd wordt natuurlijk gevorderd voor het beredeneerd overzigt van 't geen in de drie afdeelingen gedurende eenige achtereenvolgende dagen werd verhandeld; dáár waren de eigenlijke discussiën, en zijn tevens tal van stukken en memoriën overgelegd, welke door de secretarissen zullen worden vermeld, en naar gelang van zaken, geresumeerd. Dat dit alles veel tijd moet nemen, al was ook dat secretaris-werk aan uitmuntende handen toevertrouwd, laat zich gereedelijk gevoelen, vooral als men in aanmerking neemt dat het tijdperk der Tentoonstelling en de zomermaanden, juist niet de meest geschikte waren voor zoodanigen arbeid. Doch er schijnt nog een andere reden te zijn voor het lang uitblijven dier officieele verslagen. De oongressen dezen zomer in het Trocadero gehouden stonden niet op zich zelf, doch waren het gevolg van een regeeringsbesluit, en aan eenige bij decreet gestelde regelen onderworpen. Het Congres omtrent de voorzorgs-maatschappijen opende dus slechts de officieele reeks, en werd door verscheidene andere Congressen, als over demographie, den artistieken eigendom, hygieine en matigheid, en verscheidene andere opgevolgd. Het schijnt de bedoeling der Fransche regeering te zijn, de Verslagen van al die congressen gelijktijdig te doen verschijnen, waardoor dus het oponthoud tot heden zijne verklaring kan vinden. Sedert vrij ge- 
ruimen tijd evenwel worden die stukken door velen hier te lande tegemoet gezien, en heeft men dan ook in dat lang uitblijven de reden te zoeken, waarom onderstaand rapport eerst nu wordt gepubliceerd, 't geen aanvankelijk, met het oog op de spoedig verwachte openbaarmaking van den geheelen congres-arbeid, niet in de bedoeling had gelegen.

Voor het Nederlandsch publiek betreuren wij echter meer speciaal dat uitblijven, omdat de onderwerpen van Rijksspaarbankwezen, postspaarbanken en vooral schoolschoolspaarbanken een zeer belangrijke plaats hebben ingenomen, welke zaken thans bij ons geheel aan de orde zijn, zoowel door het verwachte wetsvoorstel, als door de uitvoerige behandeling van het onderwerp der schoolspaarbanken door Mr. Kerdijk in de Pragen des Tijds.

Men kan inderdaad in het welbegrepen belang der arbeidende klassen, zoowel aan de post- als schoolspaarbanken moeijelijk to groote aandacht wijden, en met regt doet dezer dagen Emile do Laveleye er het hooge gewigt van uitkomen in de Revue des deux mondes van 1 Febr.:

nQue l'ouvrier arrive a posséder un capital, et aussitôt il est converti aux idées d'ordre; il devient l'ennemi de tout bouleversement qui lui enlèverait des économies péniblement acquises. Mais comment atteindre ce résultat? En lui enseignant l'épargne dès l'enfance, afin qu'il en prenne l'habitude. Plus tard, quand le pli de la dissipation est pris, les meilleurs conseils restent stériles. Le capital créé par l'ouvrier est le seul qu'il sache conserver. C'est en vain qu'on ferait des avances aux ouvriers, comme le demandait Lassalle ou comme l'a fait l'empereur d'Allemagne sous l'inspiration de Mr. de Bismarck; elles seraient bientot dévorées, parce que l'aptitude d'en faire un bon emploi manquerait. Les sociétés ouvrières, a qui en 1848 le gouvernement avait fait des avances, ne tardèrent pas à succomber. Celles-là seules se maintiennent qui, comme les pionniers de Rochdale, ont formé leur fonds à force d'ordre et d'économie. L'épargne scolaire, ainsi qu'on peutle voir dans les rapports de Mr. de Malarce, a été introduite en différens pays notamment en France, dans beancoup de villes, et si elle peut se généraliser, les bienfaits qui en résulteront sont incalculables. Ce qui afflige le plus, quand on considère la condition des classes laborieuses, ce n'est pas tant l'insuffisance de leur salaire que le mauvais emploi qu'elles en font trop souvent. Une hausse dans la rémunération du travail 
n'aboutit ordinairement qu'à accroître les dépenses du cabaret et ainsi à dégrader l'ouvrier. C'est en vain que vous prêchez l'economie aux hommes faits. C'est une vertu d'habitude, et c'est dès l'enfance qu'il faut l'inculquer."

Zeer juist is dat gezegd. Behulpzaam te zijn tot eigen kapitaalvorming door den arbeider zelf, ziedaar het doel dat langs verschillende wegen, alle in dezelfde rigting, beoogd wordt. Dat kan niet in eens geschieden, doch vergelijking van de middelen welke proefhoudend zijn gebleken is de noodige en zekere methode.

Daarom is het voor ons publiek ran belang, om door kennisneming van den arbeid van den heer de Malarce, die zich geheel aan dit speciale onderwerp heeft gewijd, de zaak meer $a$ fond te leeren kennen, en de klippen te onderscheiden waarop men hier en daar gestruikeld is. De arbeid van den heer Kerdjjk is in dit opzigt zeer verdienstelijk, en gaarne zagen wij dien door een overzigt van het te Parijs verhandelde aangevuld. De zaak heeft meer in zich, zoowel wat de gevolgen als de uitvoering betreft, dan men soms oppervlakkig denken zou. Men kan een goede zaak door te veel jjver ook verkeerd aanpakken en daardoor voor langen tijd welligt discrediteeren. Het schoolspaarbankwezen is ten volle waard in zijne details bestudeerd te worden eer het algemeene toepassing vinde. Bedriegen wij ons niet, dan zijn wij daartoe op de goeden weg. De traditioneele regtschapenheid van onzen onderwijzersstand waarborgt ons een goeden uitslag overeenkomende met onze landaard en gewoonten, al zijn wij ook weder bij dit onderwerp, wat algemeene toepassing betreft, wat laat op de baan; want aan partieele voorbeelden, - getuigen o. a. de schoolspaarbank van meester Schaberg $\left(^{*}\right)$ to 's Hage sedert 1845 , en andere door mr. Kerdijk aangehaalde voorbeelden, - ontbreekt het bij ons niet.

Wij doen thans het Rapport volgen.

(*) Zie hieronder pag. 189. 


\section{Aan Zijne Excellentie den Minister van Finantien.}

Bij Uwer Excellentie's missive van 11 Junij ll., no. 45 Kab., uitgenoodigd, om de Nederlandsche Regering te vertegenwoordigen op het Congrès des Institutions de Préroyance, hetwelk van 1 tot 6 Julij ll. te Parijs heeft plaats gehad, heb ik bij deze de eer aan Uwe Excellentie een afschrift aan te bieden van het door mij aldaar ingeleverd rapport, en voorts aangaande het Congres en het gevolg, hetwelk door mij aan de vereerende opdragt is gegeven, het navolgende te berigten.

Het Congres werd den 1n Julij in eene zaal van het Palais du Trocadero geopend met eene toespraak van den voorzitter, den heer Hippolyte Passy, waarna ook de bestuursleden Laboulaye en de Malarce, alsmedo, daartoe uitgenoodigd, de gedelegeerden van Italie en van Nederland het woord voerden over de algemeene strekking van het Congres.

Den 2n Julij begonnen de werkzaamheden, en wel des morgens ten 9 ure in het Pavillon de Flore (Louvre) in de drie afdeelingen, waarin de congresleden zich verdeeld hadden, als: 10. Spaarbankwezen in engeren zin; 20. Sociétés de secours mutuels, Levensverzekering c. a., 3o. Verbruiksvereenigingen, Dolksbanken en dergelijke. Van 2 tot 5 ure was er dagelijks openbare zitting in het Trocadero. Van de vijf openbare zittingen, $2-6$ Julij, werden de drie eerste aan het eigenlijke spaarbankwezen gewijd, de twee laatste aan de sociétés de secours mutuels, levensverzekering, volksbanken en dergelijke. Het voorzitterschap werd waargenomen : twee dagen door leden van het Fransche hoofdbestuur, de heeren Passy en Laboulaye, de drie andere dagen door de gedelegeerden van Italie, Nederland en Duitschland.

Zoo als Uwe Excellentie uit de programma's en andere officiele stukken zal bekend zijn, gaf het Congres tot geen votams of 
resolution aanleiding, en werden ook in de publieke zittingen geen eigenlijke discussien gevoerd. Overzigten werden geleverd van den toestand en de vorderingen in de onderscheidene landen; vele documenten en statistieken zijn overgelegd, waarvan de hoofdzaken door de sprekers in hunne rede nader werden toegelicht. In de afdeelingen had meer eigenlijke discussie plaats, waarvan door de secretarissen aanteekeningen zijn gehouden, die tot een beredeneerd verslag zullen worden verwerkt.

Wat het spaarbankwezen betreft werden voor Frankrijk belangrijke overzigten gegeven, met graphische voorstellingen in de publieke zitting toegelicht door den heer de Malarce, aan wiens ijverig initiatief men vele vorderingen in het spaarbankwezen, bepaaldelijk ook voor de schoolspaarbanken, te danken heeft. Zoowel door dezen als door andere redenaars werd voorts de nieuwe rigting, die zich kenmerkt door medewerking van den Staat in verschillende vormen, uitvoerig besproken, onder verwijzing naar het Engelsche stelsel, dat in de bijzonderheden werd nagegaan. Omtrent de organisatie en de werking der Belgische en Italiaansche postspaarbanken werden belangrijke mededeelingen gedaan door den heer L. Cans, hoofddirecteur der Belgische Caisse générale d'épargne et de retraite, gedelegeerde van Belgie, en den heer Luzzati, gedelegeerde van Italie.

Eerstgenoemde vestigde onder anderen de aandacht op de in Belgie sedert eenigen tijd ingevoerde carnets de rente, waardoor de inlegger een rentedragend en verhandelbaar certificaat van inschrijving op een der grootboeken bekomt, geschiedende de aankoop on verkoop der rente kosteloos voor de inleggers; een stelsel waardoor de Staat ontheven wordt van de risico om, ook bij dalende koersen, steeds de volle geldswaarde van den inleg op aanvrage te moeten teruggeven.

De geldbeleggingen in bijzonderheden toelichtende, legde de heer Cans gunstige getuigenis af van de resultaten der Belgische Caisse générale d'épargne et de retraite en van de later daaraan toegevoegde postkantoor-spaarbanken.

In gelijken zin getuigde de heer Luzzatti van de (later ingevoerde) Italiaansche postspaarbanken, daarbij op het onderscheid met Engeland wijzende, alwaar de directe rijksbemoeijing gedeeltelijk aan het wantrouwen jegens de oude particuliere spaarbanken is toe te sohrijven, terwijl in Italie, met zeer gunstig bekende partiouliere spaarbanken, het streven naar meer gelegenheid tot inleg, meer aanrakingspunten voor het publiek, de roorname aanleiding 
is geweest tot de staatsbemoeijing, welke dan ook an de particuliere banken geheele ontwikkeling laat.

Voor Duitschland, alwaar de regering voor een paar jaren voor een stelsel van postkantoor-spaarbanken minder gunstig gezind was, schijnen in den jongsten tijd andere inzigten de bovenhand te verkrijgen. Opmerking te dien anzien verdient een rapport van den Duitschen gedelegeerde naar het Congres, den Geh. Oberc Postrath Dr. Fischer, de mededeeling inhoudende ${ }_{n}$ dat de administratie der posterijen van het Duitsche rijk oordeelt, dat eene instelling, die zooveel materiele voordeelen bepaaldelijk aan de arbeidende klassen belooft, niet langer verwaarloosd behoort to worden." Het rapport van dezen hoofdambtenaar, met ontwoerp van een stelsel van pos/spararbanken in Duitschland, is opgenomen bij de in het Fransch vertaalde brochure "Les institutions de prévoyance au profit des omployés de l'administration des postes et télégraphes de l'empire d'Allemagne", waarvan ik de eer heb bij deze een exemplaar aan Uwe Excellentie over te leggen.

Wat Nederland betreft, was ik door veelzijdige medewerking in de gelegenheid gesteld een vrij volledig overzigt te geven van onze vaderlandsche werkzaamheid, zoo op het gebied van het eigenlijke spaarbankwezen als van do overige instellingen van voorzorg.

In antwoord op eene circulaire, door mij in het voorjaar aan de voornaamste besturen gerigt, waren $m i j$ ten behoeve van het congres vele bescheiden toegezonden. In de eerste plaats noem ik daarbij het hoofdbestuur der Maatschappij tot Nut van 't Algemeen, door wiens zorg een in het Fransch gesteld overzigt van de bemoeijingen der Maatschappij was opgesteld, met verscheidene bijlagen verrijkt.

De besturen der Amsterdamsche en Rotterdamsche spaarbanken hadden ook in ' $t$ Fransch gestelde bescheiden en statistieken toegezonden; terwijl van de meeste onzer voorname spaarbanken de reglementen, verslagen met de statistieke uitkomsten der laatste jaren, in meerdere of mindere ruimte waren ingekomen.

Mr. G. A. Fokker, de onvermoeide strijder tot uitbreiding en bevordering van het spaarbankwezen, had - niettegenstaande de toenemende ongesteldheid, waaraan hij sedert bezweken is, het hem moeijelijk maakte, - eene in 't Fransch gestelde nota over den loop en toestand onzer Nederlandsche spaarbanken ingezonden.

Door medewerking van den heer Minister van Binnenlandsche Zaken kon ik een paar groote verzamelstaten van ons geheele 
spaarbankwezen, de bijzonderheden inhoudende, die in de jaarlijksche verslagen over het armbestuur voorkomen, en over de laatsto 25 jaren loopende, overleggen.

Deze stukken, bij het Congres ingediend en zoowel in de afdeelingen als bij de publieke discussien toegelicht, zijn met groote belangstelling ontvangen; vooral de vorderingen, welke in het laatste zevental jaren zijn gemaakt, ontmoetten eene welverdiende waardering.

Voor andere onderdeelen, als schoolspaarbanken (in vergelijking met andere landen bij ons nog slechts in begin), hulpbanken, spaarkassen, zieken- en begrafenisbussen, waren mede op mijn verzoek bij het Departement van Binnenlandsche Zaken verzamelstaten opgemaakt.

Op het gebied der levensverzekeringen waren door de Rotterdamsche Maatschappij, de Maatschappij Kosmos en de onlangs opgerigte Dordrechtsche Maatschappij belangrijke gegevens en overzigten verstrekt, waaronder eene belangrijke table de mortalilé door het bestuur van eerstgenoemde volgens nieuwe gegevens bewerkt en aan den heer D. I. Samot (fellow of the institute of actuaries) verschuldigd, eene speciale vermelding vordert.

Omtrent voorzorgs- en pensioenkassen voor werklieden hadden de besturen der Hollandsche, der Nederlandsche Rijn- en Centraalspoorwegmaatschappijen en der Exploitatie-maatschappij, het bestuur der domaniale mijnen te Kerkrade en eenige andere particuliere nijverheids-ondernemingen de reglementen enz. hunner instellingen toegezonden, terwijl de Fransche nota van $\mathrm{mr}$. Farncombe Sanders, door de zorg Uwer Excellentie ter Landsdrukkerij gedrukt, een naauwkeurig en zeer gewaardeerd overzigt aanbood van de Nederlandsche wetten en verordeningen omtrent de Sociétés de secours mutuels in den ruimsten zin genomen.

Uit het hiernevens overgelegde rapport zal Uwe Excellentie kunnen blijken wat door mij over deze verschillende onderwerpen is medegedeeld.

Mij daaraan gedragende, meen ik voorshands met deze mededeelingen aan Uwe Excellentie te moeten volstaan, daar toch een omstandig verslag der handelingen van het Congres in bewerking is, waarin zoowel de notulen der afdeelingswerkzaamheden, als de redevoeringen in publieke zitting gehouden en stenographisch opgeteekend, in extenso zullen worden opgenomen.

Daar mij, behalve bij de opening, in drie der opvolgende zittingen het woord werd gegeven om de Nederlandsche toestanden te 
bespreken, heb ik gelegenheid gehad om den inhoud van nevens. gaand geschreven rapport, vermeerderd met bijkomende toelichting op onderscheidene punten, geheel in de publieke zittingen uit te brengen. Het rapport zal mitsdien, over de drie zittingen naar gelang der onderwerpen verdeeld, in de gehouden redevoeringen voorkomen, terwijl ik mij intusschen de eer geef om dat stuk, in afwachting der aanstaande toezending van het officiele compte reudu, bij deze aan Uwe Excellentie over te leggen.

's Gravenhage, September 1878.

De gedelegeerde der Nederlandsche Regering, J. L. DE BRUYN Kops.

RAPPORT sommaire sur les Institutions de Préroymnce en Hollande.

Caisses d'éparyne. Linstitution des caisses d'épargne en Hollande est entièrement due à l'initiative privée. Aucune loi, aucun règlement public ne régit la matière. Cependant les banques fonctionnent bien et les pertes par suite de malversation sont inconnues. Règle générale, peut-on-dire, les caisses ont été fondées par les départements (ou sections) de la Société de bien public, existant depuis le commencement da siècle.

Dans ce résumé sommaire je ne m'arrêterai point aux détails d'administration, qu'on peut connaittre en consultant le rapport de la direction centrale de cette société, la note excellente de M. Fokker et les rapports remarquables des directions des caisses d'Amsterdam et de Rotterdam sur l'état de ces institutions pendant un grand nombres d'annces. Comme traits généraux je tiens à signaler :

10. Que l'étendue et l'intensité de l'épargne jusqu'à 1870 à peu près n'ont pas été remarquablement fortes en Hollande en comparaison de beaucoup d'autres pays, ce qui tient en grande partie au nombre restreint des caisses par rapport au territoire et à la population, et en second lieu au nombre limité des séances consacrées aux versements etc., très souvent une heure par semaine! Un changement très-heureux s'est manifesté, quant à ce dernier point, depuis six ans à peu près.

2o. Que les mouvements défavorables à constater dans l'épargne générale pour quelques époques ne sauraient être attribués à un défaut de confiance dans les gérants de ces établissements, mais aux pertes éprouvées par les déposants par suite de baisse des 
fonds publics par causes politiques, p. e. dans les années 1830, $1848,1860$.

Il me semble qu'on ne saurait éviter tout-à-fait ce danger, aussi longtemps qu'on considérera comme principe fondamental de rembourser intégralement en numéraire toutes les créances des déposants. En fixant des limites pour maximum de dépôt, en exigeant un avis préalable de plusieurs jours pour le remboursement, on diminue mais on n'écarte pas ce grand inconvénient. Tant qu'on s'obligera à restituer en argent les sommes qui, pour pouvoir porter intérêt, doivent être placées en valeurs (effets publics etc.), on court le risque d'attirer un run sur les caisses, dès qu'une baisse subite et considérable se manifeste à là bourse.

Des fonds de garantie considérables quelquefois, comme de la caisse d'épargne d'Amsterdam, fournis par un sentiment de pure philantropie ou bien par les gains accumulés des caisses mêmes, peuvent donner de la sécurité aux déposants; mais on ne fait de la sorte que déplacer la perte.

Un bon système serait, à mon avis, de donner aux déposants un titre sur le Grand Livre ou antre obligation, soit nominative soit au porteur, dès que ses dépôts atteindront le chiffre qui permet ce placement, p. e. 100 francs. En Hollande le prix d'une obligation au porteur $2 \frac{1}{2}$ pet. est selon les cours actuels à peu près 64 florins, soit 130 francs.

Les ordonnances belges me semblent réaliser ce système d'une manière heureuse, par l'introduction des carnets de rentes au porteur, selon l'arrêté royal du 13 Février 1875.

En effet, le but véritable des caisses d'épargne doit être en premier lieu de faciliter, de provoquer les petites épargnes; elles doivent aider la classe ourrière à trouver le chemin du Grand Livre et autres crédits de l'état; mais elles ne doivent pas être l'instrument officieux pour créer de petits rentiers, dont les caisses prendraient le risque et auxquels elles offriraient même l'avantage d'une petite spéculation. Non, les caisses doivent aider à former le petit capitaliste; dès que l'ouvrier s'est élevé à cette hauteur, qu'il le soit réellement et qu'il en coure lui même les risques.

En résumé, la caisse d'epargne est une banque de dépó́l de nature et de conditions spéciales, et c'est agir contre les règles d'une saine économie des banques, que de s'obliger à rembourser ex argent $c \theta$ qu'on doit placer en grande partie en valeurs non remboursables, mais soumises aux cours variables de la bourse.

3o. Jusqu'à présent le système des caisses d'épargne postales, 
inauguré par M. Gladstone et accueilli favorablement par d'autres pays, n'a pu être introduit en Hollande. Pourtant il y trouve de nombreux adhérents. Dès 1863 la revue l'Economiste s'attache à en populariser l'idée, et une discussion assez approfondie se fit jour plusieurs fois dans les années suivantes, tant dans les journaux et revues qu à la Chambre. En $1870 \mathrm{M}$. Fokker, député de Middelbourg (Zélande), saisit l'occasion de la réforme postale, en discussion à ce moment, pour proposer un article où l'établissement de ces caisses était exprimé en principe. Son amendement fut rejeté, mais la question n'en resta pas moins à l'étude tant au Ministère des Finances que dans le public. Le Ministre des Finances, M. Blussé, qui comme député avait voté contre l'amendement Fokker, déclara plus tard, comme Ministre, en réponse à une interpellation, que plus il étudiait la question, plus elle lui souriait et qu'il espérait porter un projet devant la Chambre. La durée de son ministère fut trop courte pour qu'il pat y donner suite. Son successeur, M. van Delden, se déclara en principe contre l'intervention de l'état dans cette matière. M. van der Heim, Ministre conservateur, bien connu d'ailleurs pour ses sympathies pour le progrès économique et le bien-être des classes ouvrières, tenta un terme moyen. Un arrêté royal de Décembre 1875 établit les bureaux de poste comme intermédiaires entre les déposants des diverses localités et les caisses d'épargne. Cet arrêté a été l'objet de critique aussi vives que fondées, tant de la part du public et dans la Chambre que du côté des caisses d'épargne ellesmêmes, qui presque unanimement ont dit: non tali auxilio!

Effectivement, comme l'Economiste le fit ressortir dès la promulgation de l'arrêté, cette mesure d'administration ne donnait que ce qu'on possédait déjà, e'est à dire la faculté d'envoyer le montant de sa mise par mandat de poste à la caisse d'épargne qu'on désirerait. La loi postale avait déjà réglé ces envois d'argent, la taxe à payer restait la même, et il y avait bien des formalités à remplir, tant pour les déposants que pour les caisses d'épargne elles-mêmes. Il n'est pas étonnant que la mesure resta sans effet, quand on considère que pour les petites mises, d'un franc par exemple, le droit à payer c. a. (5 centimes de Hollande) absorbait d'emblée plus de deux ans d'intérêt. Le droit fât diminué plus tard de moitié, spécialement pour les déposants aux caisses; mais encore l'effet de la mesure est à-peu-près nul. Il faudrait une loi pour accorder entière franchise de droit; mais à mon avis, même dans ce cas, on n'atteindrait pas le but: les formalités a 
remplir; le choix à faire entre les caisses d'épargne; l'intervalle souvent très-long entre la mise et le reçu du livret (bien peu de caisses ayant séance chaque jour); la différence des réglements et des conditions, tout cela rend ce système de bureanx de poste intermédiaires bien moins efficace que celui d'une caisse centrale, dont les bureaux de poste seraient les agents comptables. Pour l'administration d'ailleurs, le système anglais, où tout se concentre dans le post-office, comporte bien moins de complications que celui d'une correspondance avec un grand nombre de caisses libres, avec des réglements et des conditions différents et sans lien avec l'administration des postes.

A la fin de l'année 1877 l'administration des postes fut transférée, avec les télégraphes, au nouvean Ministère des Travaux Publics et du Commerce sous M. Tak van Poortvliet. Dans la séance de la Seconde Chambre du 15 Décembre, sur la demande de M. M. les députés Idzerda et de Bruyn Kops, le Ministre se déclare partisan d'une organisation plus efficace des bureaux de poste au service des épargnes populaires. Le système actuel (arrêté de Décembre 1875) lui semble insuffisant, les faits le prouvant d'ailleurs; car dans les 9 premiers mois de 1877 on n'avait eu que 301 mandats de poste pour le service des caisses, pour une valeur de 30 mille francs en tout $(f 15,085)$. Le Ministre, nouvellement au pouvoir, a été prudent dans sa réponse; évidemment il n'a pas voulu se lier par une promesse. Espérons! Voilà ce qu'on peut dire pour le moment.

L'hésitation, pour ne pas dire hostilité, qui se manifeste chez plusieurs au sujet du système anglais, provient à mon avis de deux sources:

10. On redoute la responsabilité que le trésor public prendrait sur lui pour le remboursement intégral en temps de crise, - objection qui peut et doit disparaître tout-à-fait par un bon ensemble de réglements et de conditions pour les déposants, comme avis préalable pour les sommes dépassant des limites indiquées, et surtout par l'adoption du système belge indiqué plus haut.

20. On craint de décourager l'iniliative privée et on combat le système postal pour l'épargne au nom du laisser faire.

A mon avis on est ici dans l'erreur, erreur doctrinaire; il ne s'agit pas d'intervenir dans une industrie privée, l'état ne veut rien défendre, rien diriger même, la liberté du travail ne serait atteinte d'aucune manière Quel est le but de tous les systèmes d'épargne comme fait social? Un but de bienfaisanco et de. EOUN. 1879, 
philantropic. Eh bien, si l'expérience nous montre clairement jour par jour, que l'épargne augmente en raison des facilités qui lui sont offertes, et que les caisses privées, fussent-elles encore plus excellentes que ne le sont déjà celles de Rotterdam et d'Amsterdam, ne peuvent jamais donner ce que l'état offre: un bureau permanent, ouvert à toutes les heures et dans toutes les localités, arec une comptabilité et un service de virements tout établis; - pourquoi de ces deux prémisses ne pourrait on conclure logiquement à l'intervention de l'état?

$\mathrm{Je}$ confesse il est vrai, c'est pieuse coutume de faire sonner la formule du laisser faire pour ce qu'on ne voudrait pas faire; mais distinguons: l'état n'entrave rien par les caisses d'épargne postales; au contraire, il ouvrirait une nouvelle voie à l'activité de la véritable philantropie, c'est-à-dire d'encourager les pennybanks, les caisses scolaires et toutes les ramifications aussi nombreuses que petites qui ne peuvent être en contact direct avec l'état, mais qui, réunies et dirigées, font la rivière bienfaisante.

On conçoit d'ailleurs sans trop de peine que les directeurs actuels de bien des caisșes, ceux qui les ont fondées peut-être, qui $\mathrm{y}$ donnent leur temps et leur peine et qui recueillent par là une considération bien méritée, ne voient pas de très-bon oeil la concurrence imminente du cassier à cent bras, qui menace de s'abattre sur sa clientèle. Qu'ils pensent toutefois, que ce sont des bras bienfaisants et forts qui désirent se mettre au service du même but qu'ils poursuivent eux-mệmes, c'està-dire de rendre le plus de service possible à des concitoyens et à la population ouvrière en particulier. Il y a toutefois bien quelques points de rapport entre les fonctions d'un grand bureau d'épargne et l'industrie privée, c'est-à dire le service de $l^{\prime}$ encaisse. Supposons que les versements se montent à 3 ou 4 millions de francs par an, la marge permanente en numéraire avant les placements définitifs sera done déjà très-considérable. En outre la réserve obligée pour le remboursement à vue présentera un chiffre imposant par lui-même, et les maisons de banque qui seront en compte courant pour ces sommes, pour les placements etc., trouveront dans l'usage de ces dépôts un grand et légitime avantage. Est.ce à dire que pour cela la question change de face et que l'état devrait s'abstenir d'utiliser ses bureaux en profit de tous, dans la crainte de diminuer peut-être dans une légère mesure les gains, fort licites d'ailleurs, que quelques particuliers tirent indirectement d'une oeuvre de pure bienfaisance? 
La réponse ne saurait être douteuse, et en outre, qu'on n'oublie pas que cet avantage d'une grande encaisse en compte courant vient dans le système des banques postales au service de tous, parce qu'elle entre dans le trésor public. L'encaisse des bureaux d'épargne (que l'état n'est pas obligé comme les directions particulières de placer en grande partie en placements définitifs) cette encaise, dis-je, constitue pour l'état une dette flottante d'une service très régulier et sous des conditions très-favorables quant à l'échéance.

Somme toute, il est à désirer qu'on cesse de voir forcément un antagonisme entre les banques privées et les caisses postales. De fait ce sont bien plutôt les premières qui font opposition au nouveau système que autrement. Jamais que je sache les partisans des banques postales n'ont proposé de restreindre ou d'entraver les banques particulières; mais ce sont ces dernières, qui disent avec une satisfaction, bien naturelle assurément: nous pouvons suffire presque tout aussi bien aux besoins des déposants que les caisses postales; nous multiplions nos séances, nous sommes pleins d'activité, et voyez comme nos dépôts augmentent."

Effectivement, Amsterdam nous montre le nombre de ses versements doublant en six ans: de 30,000 en 1871 à 58,000 en 1877; la somme des versements annuels augmentant presqu'au triple: de fl. 495,000 à fl. 1,400,000; et le total de l'avoir triplant aussi. A Rotterdam on voit la même chose: la somme des versements annuels augmente de 1871 à 1877 de 1 million de florins par an ̀̀ 2 millions (fl. $1,959,000$ ).

Si l'on remonte d'après les rapports officiels aux causes de ces progrès très-marqués, on trouvera qu ils sont attribués presque exclusivement à la multiplication des jours et heures de séances pour versements et remboursements. (Je renvoie aux annexes pour les détails.)

Ainsi à Rotterdam le nombre des séances par an augmentait pour l'époque précitée de 267 à 950 . Amsterdam aussi a graduellement augmenté ses séances, et on roit bientôt depuis 1870 une augmentation graduelle dans le nombre de versements: de 30,000 en 1871 nous arrivons à $58, \mathrm{r} 00$ en 1877 , et le total de l'avoir, qui était resté plus ou moins stationnaire de 1865 à 1870 , se trouve triplé en 6 ans depuis 1871 de fl. 948,000 à fl. 2,968,000.

On reconnait encore la même marche d'affaires et dans les rapports de La Haye par exemple et dans les tableaux concernant toutes les caisses du Royaume, pour les 30 dernières anníes, et 
que j'eus l'honneur de soumettre au Congrès. Depuis 1870 à 1875 le nombre des déposants par année s'élève de 89,000 à 149,000; les dépôts annuels de 4,000,000 de florins à $8,791,000$; le devoir total des caisses de 11 millions à 23 millions de florins. Partout donc on voit une augmentation sensible depuis 1871-1872, partout une activité renaissante et augmentation des recettes et du nombre des déposants; partout enfin l'augmentation du nombre des séances qui est signalée comme cause.

Eh bien, l'hommage sincère que cette activité mérite sans aucun doute et que nous accordons bien volontiers, ne nous empêchera pas de dire que selon nous, ce réveil de l'activité privée sur le champ de l'épargue et ces beaux résultats sont un argument des plus marquants pour les caisses postales. Car à quoi les attribuer ces résultats bienfaisants, si-non à l augmentation du nombre des séances, qui certainement donnent presque tout ce que, dans la mesure du raisonnable, on peut demander à la philantropie individuelle.

Eh bien, disons nous, si la légère augmentation des points de contact, des occasions d'épargne que nous signalons, a déjà pu produire des effets si remarquables, que sera-ce donc si l'occasion est doublée, quintuplée, centuplée même, par le mécanisme des bureaux de poste, la caisse perpétuelle?

Plus les banques se sont évertuées à suffire à tous les besoins, plus elles ont donné par là même des arguments pour l'intervention de l'état, qui seul peut offrir sur une large échelle ces conditions que les banques, même les plus actives, ne sauraient jamais donuer qu'en partie.

Et, chose curieuse en effet, d'où date-t-il ce réveil si remarquable? Les tableaux nous le disent: pour Amsterdam, pour la Haye, pour Rotterdam c'est depuis 1870 ou 1871, e'est-à-dire depuis la proposition Fokker et la discussion dans les Chambres, ce qui ramena forcément l'attention publique sur l'importance du principe nouveau et qui éveilla une noble rivalité chez les banques particulières.

En résumé, voici donc, messieurs, où nous en sommes pour les caisses d'épargne: Une amélioration sensible depuis les six dernières anuées, augmentation de versements, de livrets, de capital. Pas la moindre hostilité des partisans des caisses postales contre les caisses privées, mais par contre une sorie d'inquiétude parmi celles-ci de voir leur domaine amoindri, - inquiétude se manifestant par une rivalité honorable contre le nouveau principe, 
mais par cela même fournissant de jour en jour plus d'arguments à ceux qu'elles considèrent comme leurs adversaires.

Si vous me pardonnez, messieurs, de m'être étendu un peu longuement sur ce sujet, je tâcherai de me montrer digne de cette indulgence en me limitant autant que possible pour les points que j'ai encore à traiter.

Epargnes des écoles. Les caisses scolaires existent chez nous. Il est même digne de noter, que dès l'année 1845 la première de ces institutions connue en Hollande fut fondée le 1er Novembre dans une école d'enfants pauvres, école de la diaconie de l'Église Réformée à La Haye, par l'instituteur J. P. Schaberg. Dans l'espace d'une vingtaine d'années (1858-1877) cette caisse scolaire remboursa aux élèves ou anciens élèves la somme de fl. 6096 . Dans le cours de l'année 1877 les versements ont atteint fl. 372 (à p.p. 760 francs) et à la fin de l'année le capital des déposants se montait au total à près de fl. 2000 (ou 4000 franes). Uu tableau général qui m'a été communiqué par M. le Ministre de l'Intérieur, me dit qu'il y a pour 1877 dans tout le royaume 93 caisses scolaires avec 20,148 participants, dont les dépôts s'élèvent à fl. 53,717 ou 112,000 francs.

93 écoles où l'épargne est installée c'est bien peu pour les 4000 écoles primaires de notre pays, - mais e'est quelque chose, e'est un commencement. Les instituteurs sont en général pleins de zèle et ne reculent pas devant les embarras, inévitables pour une école nombreuse. Dans le tableau susmentionné je trouve un grand chiffre de remboursement: fl. 30,866 sur fl. 53,717. Mes informations m'ont appris qu'effectivement les sommes épargnées sont souvent redemandées quand l'enfant quitte l'école, soit par les parents soit par les enfants mêmes. Toutefois les maîtres ne considèrent pas ceci comme bien grave En premier lieu ces retraits ont lieu le plus souvent pour des dépenses utiles, et puis, en tout cas, l'enfant a appris à épargner; il a vu, il a senti pour ainsi dire, le bienfait d'une abstention de dépenses et de la modération dans les désirs. Cet effet moral est le principal.

Une observation générale en consultant les tableaux des caisses d'épargne de la Hollande, est que le rapport défavorable des déposants à la population se trouve considérablement modifié, quand on prend le rapport à la population des communes où se trouvent les eaisses d'épargne. Ce rapport défavorable est une accusation contre le petit nombre de caisses qu'on a établies; il 
n'est aucuricment une preuve d'un esprit d'imprévoyance. Dans le Limbourg par exemple, on trouve 4 déposants par mille habitants, chiffre extraordinairement bas, mais le fait est qu'il ne se trouve qu'une seule caisse d'épargne - à Maestricht - pour toute la province avec ses 232,000 habitants. Si on compare le nombre des déposants avec celui de la population dans la commune où se trouve la caisse, on constatera 80 déposants par mille habitants.

D'après la statistique abstraite, la proportion pour les autres parties de la province serait donc 0 . Ces personnes n'épargnentelles point? Ce serait bien hasardé de dire. On doit considérer aussi que la population agricole très-souvent épargne sous autre forme que par dépôt à la caisse, o'est à dire par le bétail engraissé, le porc, la chèvre achetée; voilà souvent l'épargne du pauvre cultivateur et de mainte famille de journalier.

Caisses pour achat de provisions. Outre les caisses d'épargne proprement dites, la Hollande connait des caisses spéciales pour achat de provisions. Les mises et contributions régulières des membres sont administrées par la direction, qui achète des provisions pendant le cours de l'année au meilleur prix possible, et les distribue en hiver aux membres, au pro-rata de leurs créances. Cette combinaison permet ainsi aux petites bourses de profiter sur les prix, par l'achat de première main par grandes quantités.

Une trentaine de ces caisses existent dans le pays, avec 7 à 8000 membres. Le nombre ne va pas en augmentant; mais les mises et contributions montrent un accroissement progressif: de fl. 90,000 en 1867 à fl. 157,000 en 1874 .

L'achat de provisions n'est du reste qu'une des formes d'épargne de ces caisses, qui fonctionnent aussi comme caisses d'épargne ordinaires. L'achat de provisions ne forme qu'une petite partie des dépenses et va en diminuant de fl. 39,000 en 1864 jusqu'à fl. 10 à 11,000 dans les dernières années. Les détails de l'administration sont consignées dans les tableaux statistiques annexés.

Les banques d'avances pour ouvriers (Hulpbanken, banques de secours) sont encore une création de la Société de Bien Public. La prémière fut fondé à Middelbourg, si je ne me trompe, principalement sur l'initiative de M. Fokker.

Ces banques fonctionnent presque toutes selon les mêmes règles. Elles ont un capital par actions, qu'elles augmentent quelquefois par des obligations à rente fixe et par des emprunts faits à d'autres fondations charitables, comme caisses d'épargne etc. Elles sont administrées gratuitement et $t$ ennent séance à jours fixes, 
une fois par semaine par exemple. Elles font des avances sur cautionnement de deux personnes connues et accréditées; on augmente l'avance avec l'intérêt, ordinairement 4 pour cent, pour la durée du prêt, et le total est remboursé en payements égaux chaque semaine, à commencer 6 semaines après l'obligation souscrite. C'est le système des annuités en petit. On ne prête que pour affaires de petit commerce, achat d'outils etc.; le maximum du prête vari et va jusqu"à fl. 300 ou fl. 500 (mille francs); le remboursement intégral doit toujours avoir lieu avant l'espace d'une année évolue. On est strict sur le cautionnement; si le débiteur fait défaut pendant 4 termes consécutifs, la dette est recouvrée intégralement sur le cautionnement, d'après les règles du Code Civil.

Ces banques ont assez bien pris. Il y en a actuellement 46 , fonctionnant avec un capital d'un million de francs à peu près; le nombre des avances est de 8000 par an, faites à 6500 personnes; la moyrune des avances par personne, augmentant graduellement, est de fl. 110 ; le total des avances de fl. 723,000. L'intérêt servi par les emprunteurs varie de 2 à 5 pet.; mais par la combinaison des payements fixes, pour remboursement et intèêt, l'intérêt servi est de facto plus élevé et va jusqu'à 7 pct., quand l'intérêt stipulé n'est que de 4 pct. On n'a d'ailleurs pas à se plaindre de ce taux d'intérêt, le petit commerce, pour lequel les avances doivent servir, rapportant des intérêts bien plus élevés, de 25, 50 ou 100 pet.

Comme l'administration est gratuite, une banque populaire peut, si elle n'agit pas imprudemment avec les cautionnements, servir un assez bon intérêt à ses actionnaires et payer de 2 à 6 pct. de dividende. D'après les tableaux la moyenne de rente pour actions et obligations semble être à peu près de $4 \frac{1}{2}$ pct.

Les caisses de scoours en cas de maladie et pour frais d'enterrement sont des sociétés de secours mutuels, sur lesquelles on trouve des détails législatifs et historiques dans la note intéressante de $\mathrm{M}$. Farncombe Sanders, communiquée au gouvernement d'Italie et imprimée pour le congrès actuel par les soins du gouvernement hollandais; elle se trouve parmi les annexes. Ces sociétés ont pour la plupart un cercle d'action assez restreint; elles fonctionnent en partie comme sociétés mutuelles d'assurance sur la vie; mais par le petit nombre de membres et le défaut de base scientifique pour les tables de mortalité, conditions etc., elles ont parfois un caractère aléatoire qui a fait subir des pertes à la classe ouvrière, 
même avec des gérants de bonne foi Les statistiques officielles nous disent que le nombre de ces caisses est actuellement (1875) de 375; mais comme 111 de ces établissements n'ont donné que peu ou point de renseignements, les données des rapports ne concernent probablement que 264 de ces caisses. Le nombre des sociétés n'augmente pas; mais le nombre des membres montre un accroissement assez sensible: de 400,000 en 1862 il s'est élevé à 591,000 pour 1875 , soit à peu près $15 \mathrm{pCt}$. de la population. Les contributions ordinaires se sont élevées de fl. $1,077.000$ en 1862 à fl. $1,594.000$ en 1875. Le total des secours accordés a été en 1875 fl. 1,406.000, dont la grande moitié, ou fl. 813,000, pour frais d'enterrement. Le nombre des personnes secournes est de 66,000 , soit $11 \mathrm{pCt}$. des membres, et la moyenne des secours accordés fl. 21 par tête.

Pour plus de renseignements je dois renvoyer aux rapports officiels déposés et à la notice de M. Farncombe Sanders.

Outre ces caisses ordinaires pour frais de maladie etc., il importe de constater que dans bon nombre d'établissements industriels, fabriques, chemins de fer, chantiers de construction, il existe des sociétés de secours entre ouvriers, très-souvent sous le patronage et la gérance des chefs de l'établissement.

Ces sociétés, dont les revenus se trouvent souvent assurés par une retenue régulière sur les salaires de la semaine, peuvent être regardées comme très bienfaisantes. Elles sont souvent caisses d'épargne, d'achat de provisions, de secours en temps de maladie et caisse de retraite en même temps. Elles établissent un lien de confiance entre l'ouvrier et le patron et ont une bonne influence de toute manière.

Il est difficile de donner un aperçu du nombre et de la nature diverse de ces formes d'association. Je tiens toute-fois à fixer l'attention du Congrès sur les institutions de ce genre parmi les employés des compagnies de chemins de fer. Les directions des chemins de fer Hollandais, du Central, du chemin de fer Rhénan et de la Compagnie d'exploitation des lignes de l'Etat, se sont empressées, à ma demande, de mettre leurs règlements etc. à la disposition du Congrès.

Le directeur des mines de houille de Kerkrade dans le Limbourg, M. l'ingénieur van der Elst, a eu la satisfaction d'établir une société de secours mutuels parmi les mineurs, qui fonctionne depuis des années et après bien des difficultés vaincues, à la grande satisfaction des membres et de la direction. Une notice avec les 
règlements etc. sont déposés au Congrès, ainsi que des renseignements concernant quelques autres établissements.

Sociétés d'assurance sur la vie. On peut dire que notre législation est arriérée quant à ce point capital des sociétés de préroyance. Les ordonnances qui régissent la matière sont deux arrêtés royaux de 1830 et 1833 , établissant un système préventif qui a persisté jusqu'à ce jour. Outre l'assentiment royal requis pour toutes les sociétés anorymes par le code de commerce, les sociétés d'assurances sur la vie sont soumises à l'approbation préalable quant ì leurs tables de mortalité, le placement de fonds et autres conditions statutaires énumérées dans les arrêtés. Si ces ordonnances, pleines de bonnes intentions, peuvent avoir servi dans leur temps à prévenir quelques-unes de ces entreprises hasardées dont le public ne reconnaît que trop tard l'insolvabilité, bien des voix se sont élevées dans les derniers temps contre ce système, d'autant plus onéreux pour les compagnies, qu'il n'est pas appliqué aux compagnies étrangères, dont les agents font beaucoup d'affaires en Hollande, sans que les tables aient été soumises à aucun examen par l'autorité. Si le gouvernement est sévère par devoir dans son appréciation des tarifs, cette sauvegarde vraie ou supposée ne retiendra pas les personnes qui recherchent avant tout le bon marché et à qui un vaste champ est offert pour la participation à primes basses et selon des tables de mortalité basées sur d'autres données que celles de notre population.

Evidemment la système anglais avec publicité obligíe et dans les formes preserites par la loi, est bien préférable au nôtre, qui règle beaucoup .... excepté la publicité.

$\mathrm{Au}$ reste le ministère actuellement au pouvoir s'est déjà prononcé en condamnant le principe des réglements de 1830 et 1833 , et on doit espérer qu'une nouvelle organisation, se rapprochant du système anglais et faisant appel au contrôle du public, tant sur les sociétés nationales que sur les śtrangères, ne se fera plus longtemps attendre.

Nous avons quelques grandes compagnies d'assurances sur la vie. Je citerai la Société hollandaise à Amsterdam, fondée en 1807 et qui eut longtemps le monopole jusqu'en 1862 et 1863 , époque vers laquelle la société „Nederland" à Amsterdam, la Banque Nationale d'assurances sur la vie à Rotterdnm, et „Kosmos" à Zeist furent fondées. Plusieurs de ces directions donnent un exemple louable de confiance dans la publicité, témoins les mémoires concernant leurs assurances, que j'ai l'honneur de soumettre au 
Congrès. La société hollandaise d'Amsterdam m'écrit par contré, en réponse à ma demande de recevoir les conditions dassurance et autres imprimés, que le conseil de direction a résolu de ne pas accéder à cette demande. On me dit que cette crainte de la publicité est dans les traditions de la compagnie, ce qui est d'autant plus regrettable, qu'elle jouit de beaucoup de considération et est reconnue généralement comme très-solide.

Outre les quatre compagnies citées, il en est plusieurs autres soumises également au contrôle préventif; mais ce sont de petites sociétés se rapprochant plus ou moins des caisses de secours pour frais d'enterrement etc., catégorie qui par exception spéciale est exempte de l'examen préalable, tout comme les caisses particulières pour ouvriers d'une même profession dans la commune.

Cette exception est d'autant plus dangereuse, que les petites sociétés contiennent inévitablement un élément d'incertitude et par là de faiblesse, à cause du petit nombre de vies sur lequel la chance repose. Par les facilités comparativement grandes, qui par les décrets sont accordées justement aux sociétés de ces catégories, on stimule leur établissement, et bien des grandes pertes ont eu lieu dans la classe ouvrière, attribuables à cette cause.

On profitait quelquefois de la formule d'assentiment royal, que le Code de commerce requiert simplement pour toute société anonyme, et qu'on présentait au public comme approbation des tables de mortalité et autres conditions!

Voilà, messieurs, ce que j'ai à rapporter en grands traits sur les diverses formes des sociétés de prévoyance dans notre pays. Je désire ajouter quelques mots sur deux Institutions qui s'y rattachent indirectement: les banques de crédit foncier et les sociétés coöpératives.

Banques de crédit foncier. Le système d annuités de ces banques, pour le payement de la dette hypothécaire, contenant un amortissement progressif, peut les faire classer parmi les institutions de prévoyance.

Elles diffèrent en cela des opérations de banques ordinaires, qu'elles aident directement le débiteur à créer un capital par l'épargne.

Il existe en Hollande depuis une vingtaine d'années deux grandes institutions, la Banque Hypothécaire Nationale à Amsterdam, due à l'initiative de Mr. Sarphati; quelque temps après fut fondée la Banque Hypothécaire de Rotterdam, et très récemment enfin une troisième banque a été constituée à Amsterdam. 
Le fonctionnement de ces deux banques considérables est à peu prés le même. Elles prêtent sur hypothèque de terrains bâtis et autres, à peu près aux deux tiers de la valeur taxée. L'emprunteur acquitte sa dette par le payement d'annuités fixes, comprenant l'intérêt et l'amortissement. Pour ces avances elles émettent des lettres de gage à intérêt fixe $\left(4,4 \frac{1}{2}\right.$ ou $5 \mathrm{pCt}$.) jusqu'au montant des sommes prêtées, et qui sont sujettes au remboursement en accord avec le remboursement de ces dettes; de sorte que la banque sa borne p. a. d. au rôle de simple intermédiaire entre les emprunteurs et les prêteurs du public. L'intérêt des prêts hypothécaires et des lettres de gage est le même, les profits de la banque consistant presque entièrement dans un percentage pour frais d'administration, qui forme un élément séparé (le $3 \mathrm{me}$ ) dans l'annuité fixe. Les banques donnent toute publicité à leurs opérations. Ensemble elles placent à peu près 4 millions de florins sur hypothèque par an, et le total des lettres de gage en circulation à ce moment est à peu près de 20 millions de florins.

Sociétés Coöpéralives. Outre les banques populaires déjà citées, il existe un nombre assez considérable de sociétés fondées plus ou moins sur l'excellent modèle des banques allemandes de $\mathbf{M}$. Schultze Delitsch et qui sont: réunions pour consommation, pour simple épargne et aussi pour avances. Ces unions de crédit prennent depuis quelque temps la forme coöpérative pure, depuis que la loi de 1875 a réglé cette nouvelle forme de société. Jusqu'alors ces sociétés étaient soit des sociétés anonymes, soit des associations simplement reconnues par l'état comme personnes juridiques d'après la loi organique de 1855 sur le droit de réunion.

Le nombre de nos sociétés coöpératives pures est encore assez restreint: il $\mathrm{y}$ en a une vingtaine; mais il est à espérer que la population ouvrière comprendra de plus en plus les avantages de ces unions productives, et qu'elle travaillera aussi par ce moyen à l'avancement du bien-être matériel.

Juin 1878.

Le délégué du Gouvernement Hollandais, J. L. DE BruYn Kops. 